\title{
TOWARDS A MODEL TO PREDICT BLAST PROPAGATION AROUND A HEMICYLINDRICAL BARRIER
}

\author{
S. TRÉLAT ${ }^{1}$, M.-O. STURTZER ${ }^{2} \&$ D. ECKENFELS ${ }^{2}$ \\ ${ }^{1}$ IRSN, Institut de Radioprotection et de Sûreté Nucléaire, France. \\ ${ }^{2}$ ISL, French German Research Institute of Saint-Louis, France.
}

\begin{abstract}
Understanding the effects of blast generated by an accidental or a terroristic explosion nearby a critical structure is a main concern for the French Institute for Nuclear Safety (IRSN) and the French-German Research Institute of Saint Louis (ISL). Full-scale reactive phenomena are however seldomly compatible with long-term studies due to cost and regulation issues. Reduced scaled experimental work consequently represents an attractive alternative. Using small plastic explosive charges, blast effects in free-field or around various obstacles based on reference structures can be repeatedly examined, in order to provide the data necessary to develop simplified and numerical models. Following previous work on this topic by IRSN using a blast table and $42 \mathrm{~g}$ Hexomax ${ }^{\circledR}$ charges placed on its surface, ISL modified one existing blast pad to reproduce the same configuration at a double scale ( $333 \mathrm{~g}$ charges of Hexoma $\left.x^{\circledR}\right)$. This study was conducted using a reference hemicylindrical obstacle, commonly encountered on industrial sites and also representative of certain transport containers. Numerous pressure sensors installed within the table or the pad thickness and on the surface of the hemicylinders provided the overpressure evolution for different values of the charge to obstacle distance. Explosive charges were ignited at distances up to $3.5 \mathrm{~m} / \mathrm{kg}^{1 / 3}$ from the obstacle at ISL scale to extend the applicability domain of the model described in our previous document (Trélat et al. [18]) at a larger scale. The objective of this work is to assess not only blast effects on a potential target but also its capability to modify the blast propagation in its downstream space.

Keywords: blast, hemicylinder, high explosive, Mach reflection, scaled experiments.
\end{abstract}

\section{INTRODUCTION}

The Institute for Radiological Protection and Nuclear Safety (IRSN) is a French public institute with industrial and commercial activities, placed under the joint authorities of the Ministries of Defence, Environment, Industry, Research, and Health. IRSN is entrusted, among others, to assess and conduct researches in the area of the protection of nuclear facilities and transport of radioactive and fissile materials against accidental and malicious acts. In this context, IRSN establishes projects and studies to improve its knowledge of blast characteristics and weapons effects.

The French-German Research Institute of Saint Louis (ISL) is a bi-national research institute established by the Federal Republic of Germany and the French Republic on the basis of a treaty signed in 1958. The core mission of ISL is as follows: "Research, scientific studies and basic predevelopment in the field of defense and security." Among other tasks, ISL focuses on the physical protection of personnel and assets against the effects of various explosive charges. To improve general survivability, fundamental studies on blast wave propagation and target interaction are continuously being conducted at ISL. 
In 2006, IRSN designed and built an experimental set-up to achieve non-destructive shock wave propagation studies on a small scale $[1,2]$. This set-up is composed of a modular table, sensors and targets able to perform the detonation of solid explosives up to $64 \mathrm{~g}$ of TNT equivalent, representing an alternative to the gas mixture detonation propagation configuration for small-scale tests [3, 4]. Blast generated by 50-g TNT equivalent hemispherical Hexomax ${ }^{\circledR}$ charges was consequently characterized. To evaluate the effect of scale, a joint study between IRSN and ISL was initiated in 2017, based on a dedicated ISL blast pad replicating the IRSN table at a double scale: 400-g TNT equivalent hemispherical Hexomax ${ }^{\circledR}$ charges are being investigated [6].

In a previous document, Trélat et al. [18] proposed the innovative Model S describing the evolution of the maximum overpressure on the diffraction portion of a wooden hemicylindrical obstacle $(0.4 \mathrm{~m}$ diameter and $1.6 \mathrm{~m}$ long) exposed to a 3D blast wave. In our approach, obstacles are supposed to be non-deformable. Overpressure evolution along the circumference line facing the explosive charge was determined for $42 \mathrm{~g}$ Hexomax charges (50-g TNT equivalent in overpressure). Results were confronted to literature models (TM5-1300 [9] for reflected overpressures in full black lines and Kinney-Graham [8] for free-field overpressures in dashed black lines), leading to a good agreement between the experimental data and the prediction on the blast-exposed face of the hemicylinder. Trélat [18] addressed the expansion side of the obstacle by proposing a physical conjecture named Model S: the transmission coefficient is represented as a function of a geometrical parameter based on the obstacle dimensions (reduced shifted direct distance or RSDD on Fig. 1) as seen on Fig. 2. The introduction of this parameter enables to take into account obstacle geometry and wave diffraction along its surface. This model is valid for RSDD $\geq 0$ and three distances $(0.4,0.6$ and $1.6 \mathrm{~m})$ at IRSN scale. This document presents new experimental data obtained at ISL larger scale $(0.8,1.2,2$ and $3.2 \mathrm{~m})$ used to extend the model applicability domain, that is, to verify Hopkinson principle in close range.

An alternative model could also be based on the use of the parameter $\mu$.

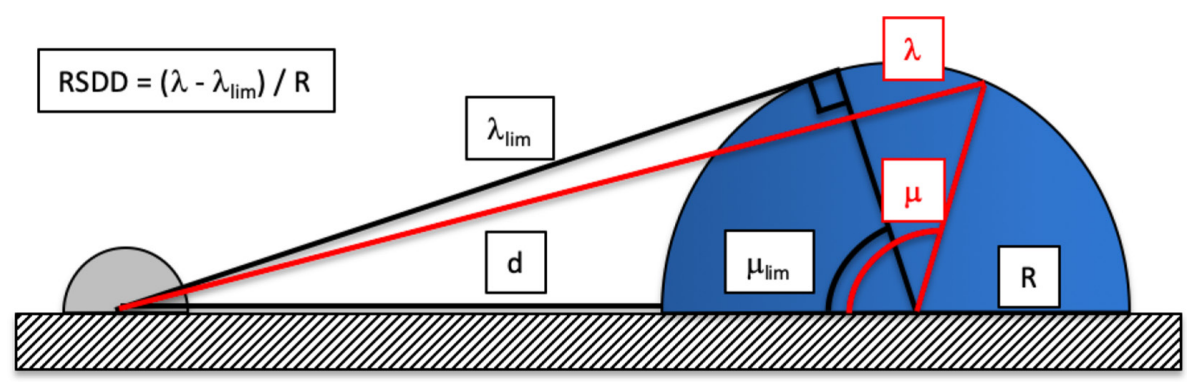

Figure 1: Experimental configuration and definition of reduced shifted direct distance (RSDD) at current point $(\lambda, \mu)$. 


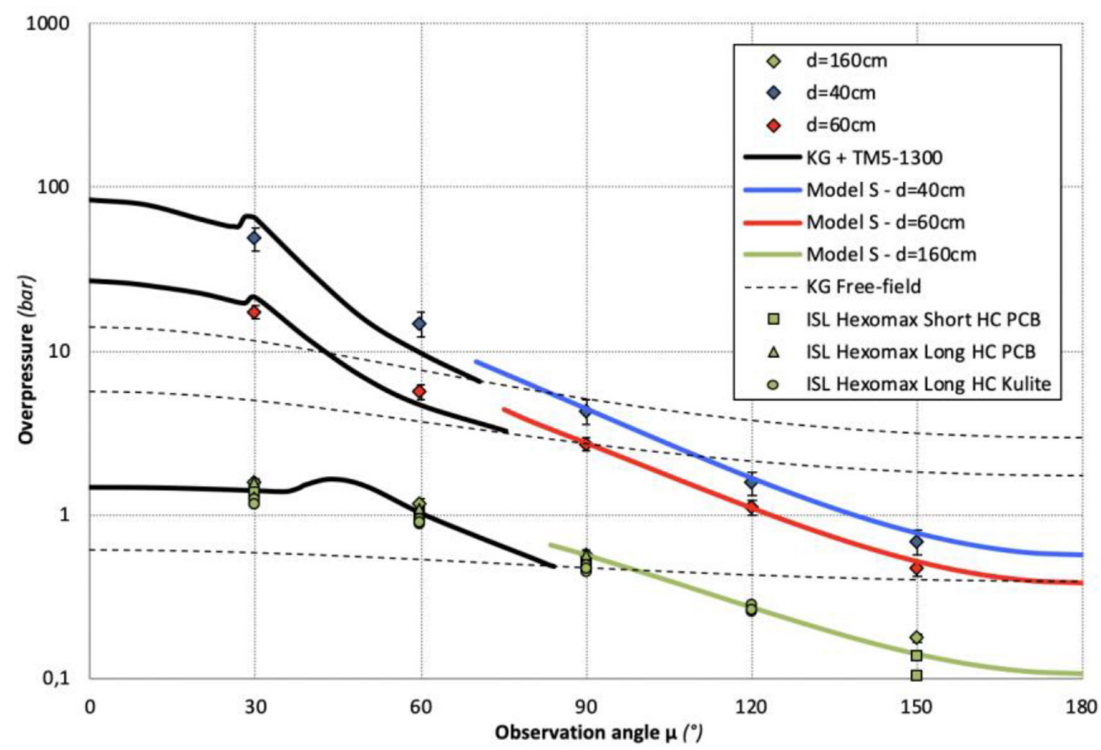

Figure 2: Peak over-pressure versus angle of observation on the hemicylindrical obstacle experimental IRSN/ISL data vs. Model S [18].

\section{EXPERIMENTAL SETUP}

\subsection{Blast pad}

Based on IRSN blast table [1, 2, 14, 18], ISL modified an existing concrete blast pad seen on Fig. 3 to conduct similar experiments at larger scales: explosive charges with a mass multiplied by 8 are ignited on a factor 2 up-scaled version of IRSN test table. The explosive charge is set on a specially reinforced metal ground plate to generate a hemispherical blast. ISL also machined a corresponding up-scaled steel hemicylinder $(0.8 \mathrm{~m}$ diameter and $0.8 \mathrm{~m}$ long) (Fig. 3) bolted onto the concrete pad. This document presents the results obtained for the first

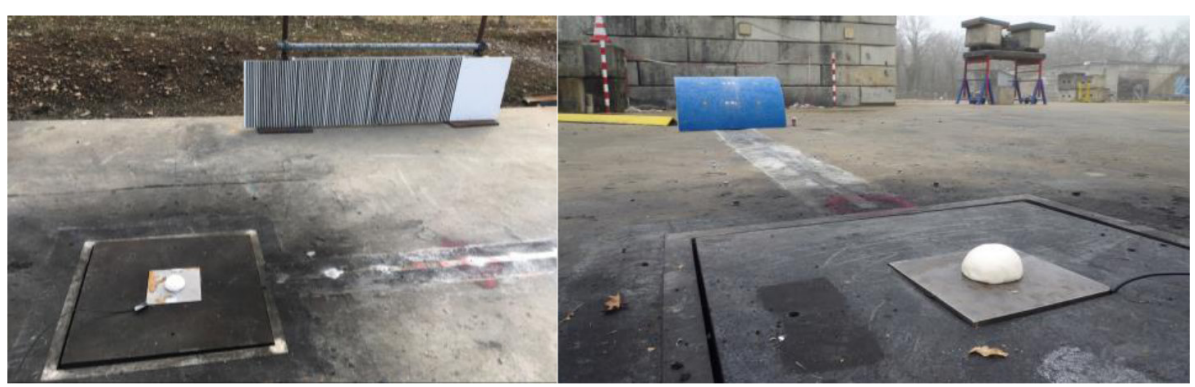

Figure 3: ISL blast pad and short cylinder setup. 
Table 1: Hemicylinder tests specifications.

\begin{tabular}{|c|c|c|c|c|}
\hline Test \# & \#2237 & $\# 2244$ & \#2252 & \#2259 \\
\hline Angle $\mu$ & \#2238 & $\# 2245$ & $\# 2253$ & $\# 2260$ \\
\hline $30^{\circ}$ & 113B28 & 113B28 & 113B28 & M102A05 \\
\hline $60^{\circ}$ & 113B28 & 113B28 & 113B28 & 113B28 \\
\hline $90^{\circ}$ & $113 \mathrm{~B} 28$ & 113B28 & 113B28 & 113B28 \\
\hline $120^{\circ}$ & $113 \mathrm{~B} 28$ & $113 \mathrm{~B} 28$ & 113B28 & 113B28 \\
\hline $150^{\circ}$ & 113B28 & 113B28 & 113B28 & 113B28 \\
\hline $\mathrm{d}(\mathrm{m})$ & 3.2 & 2 & 1.2 & 0.8 \\
\hline
\end{tabular}

series of experiments conducted on the obstacle composed of one $0.8 \mathrm{~m}$ long segment, while the three others were still being manufactured.

Table 1 summarizes the different distances d (Fig. 1) between the explosive charge and the target front surface.

\subsection{Pressure sensors positions}

PCB 113B28 (344.7 kPa) [19] and M102A05 (690 kPa) [20] piezoelectric pressure gauges were installed in polypropylene inserts equipping the $30^{\circ}$ spaced hemicylinder ports. All data were recorded and filtered (5th-order Bessel, $500 \mathrm{kHz}$ ) by a Transcom recorder at $2 \mathrm{MHz}$. Table 1 presents the position of all sensor references for the different tests.

\subsection{Explosive charges}

The explosive charges consisted of $333 \mathrm{~g}$ of Hexomax ${ }^{\circledR}$ hemispheres (400-g TNT equivalent in peak overpressure), ignited from the ground surface using an high-voltage RP83 detonator, inserted through the metallic support plate. Each charge (repeated twice for each distance for reproducibility) was placed directly on the blast pad surface as seen on Fig. 4. Charges geometric characteristics are presented in Table 2.

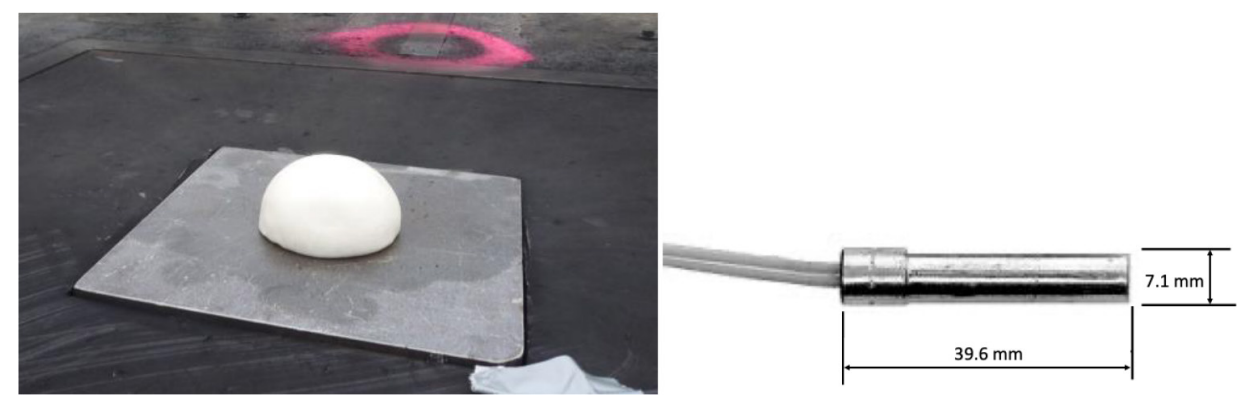

Figure 4: $333 \mathrm{~g}$ Hexomax ${ }^{\circledR}$ charge and RP83 detonator. 
Table 2: Explosive charges characteristics.

\begin{tabular}{ll}
\hline Configuration & ISL \\
\hline Mass $(\mathrm{g})$ & 333 \\
Diameter $(\mathrm{mm})$ & 94 \\
Density $\left(\mathrm{g} / \mathrm{cm}^{3}\right)$ & 1.54 \\
Igniter & RP83 \\
Reactive mass $(\mathrm{g})$ & 1 \\
(\% of total charge mass) & $(0.3 \%)$ \\
Overpressure TNT eq. $(\mathrm{g})$ & 400 \\
\hline
\end{tabular}

\section{EXPERIMENTAL RESULTS AND ANALYSIS}

\subsection{Peak overpressure on the front side of the hemicylinder}

To illustrate the data acquired during this campaign, overpressure versus time evolutions recorded for the two tests at $2 \mathrm{~m}$ at $\mu=30$ and $60^{\circ}$ are presented on Fig. 5. These sensors are installed on the exposed side of the hemicylindrical target. Peak overpressure values decrease as the blast wave propagates along the obstacle. Pressure profiles at $30^{\circ}$ demonstrate non-classical Friedlander evolutions: for example, twin peaks seem to be visible for \#2245. In this case for example, the maximum overpressure is taken for shock \#2 higher than shock \#1. This type of phenomenon may be due to the presence of conical shocks generated by fragments of the detonator metallic envelope or small projected stones, especially in close range, before they are stopped by aerodynamic drag. Such complex shock front interaction was identified in our previous work [7], as shown on Fig. 6. The pressure signal at $60^{\circ}$ appears to be less affected as they display a single shock front followed by a more standard pressure decay, leading to the hypothesis that the initial perturbation source was travelling close to the ground surface or progressively slowing down [16].
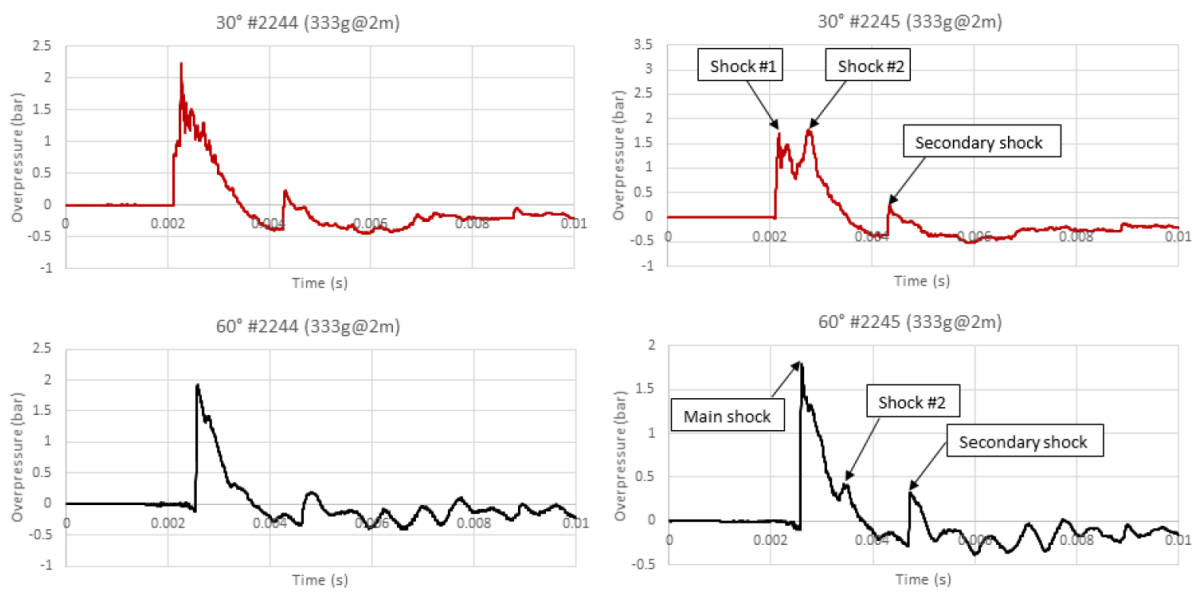

Figure 5: Overpressure time evolution at $\mu=30$ and $60^{\circ}$ for $\mathrm{d}=2 \mathrm{~m}$. 


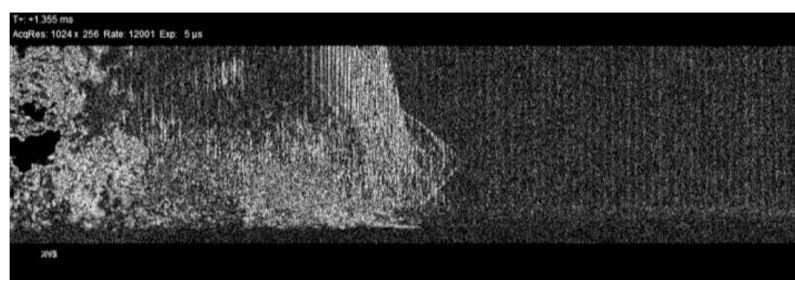

Figure 6: Complex blast: interaction between conical shock and main blast wave [7, 15].

Sound waves transmitted through the ground and the obstacle itself [22, 23], propagating at few thousand meters per second, have two types of effects:

- initial overpressure oscillations before the main shock arrival, especially for sensors used at low levels of pressure in comparison with their range, and

- later vibrations potentially amplified by resonating pressure transducers (visible at $60^{\circ}$ for both tests).

\subsection{Hemicylinder back side overpressure evolution}

Overpressure versus time evolutions recorded for the two tests at $2 \mathrm{~m}$ for $\mu=90,120$ and $150^{\circ}$ are presented on Fig. 7 as an example. These sensors are located on the expansion side of the hemicylinder. Peak overpressure progressively decreases as the blast wave propagates behind the obstacle, due to spherical expansion and diffraction phenomena [11]. Signal
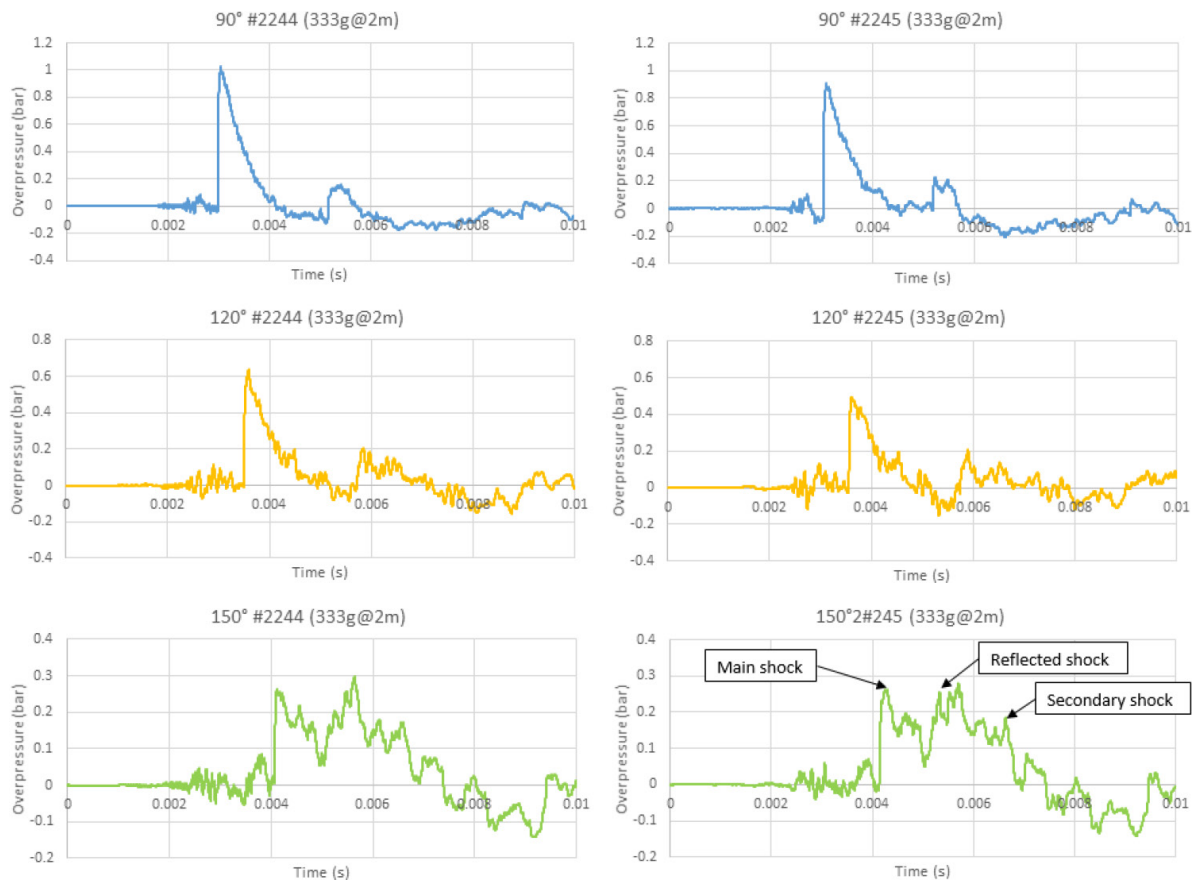

Figure 7: Overpressure time evolution at 90,120 and $150^{\circ}$ for $\mathrm{d}=2 \mathrm{~m}$. 
oscillations generated by the metallic structure vibrations and the sensor potential resonance are especially visible at $150^{\circ}$. It is however possible to detect the presence of a second peak corresponding probably to backward crossing main shock reflected on the ground surface behind the cylinder. This reflected wave precedes the frontward propagating secondary shock and interacts with the waves laterally bypassing the obstacle. The chosen maximum overpressure at $150^{\circ}$ is extracted from the first peak corresponding to the main shock.

\subsection{Overpressure versus angle at $2 \mathrm{~m}$}

Overpressure variations along the central circumference line versus the observation angle are reported on Fig. 8 for the distance $\mathrm{d}=2 \mathrm{~m}$. Peak values decrease as angular position increases along the obstacle as expected (except for one double peak measurements at $30^{\circ}$ ), before transitioning to the expansion on the backside [12]. A model [8-10] describing the overpressure on the front face is represented in black lines: reflection coefficients are determined for any cylinder point, considering its distance to the charge and local incidence to the surface, and using TM5-1300 local approximation. These representations are limited to the reflection face of the obstacle, as the model does not predict the wave expansion on the opposite side. Finally, the Model $S$ is plotted for angle values above the vision limit, that is, for RSDD $\geq 0$. Comparison of overpressure measurements with Model S can also be displayed as the transmission coefficient evolution versus the RSDD as presented on Fig. 9 for the distance $\mathrm{d}=2 \mathrm{~m}$. This coefficient corresponds to the ratio between the recorded and the free-field predicted [8] overpressures at the considered position (direct distance from the charge to the sensor position). On the obstacle expansion side, the transmission coefficient demonstrates the obstacle capability to mitigate the peak overpressure by diffracting the incoming blast wave. We observe that overpressures measured at $30^{\circ}$ are significantly below the KG + TM5-1300 model. We remind that TM5-1300 model is defined for reflected waves on planar surfaces. The discrepancies between model and experimental data could be due to the hemicylinder curvature and the consequent wave incidence variation [13]. This issue should be specifi-

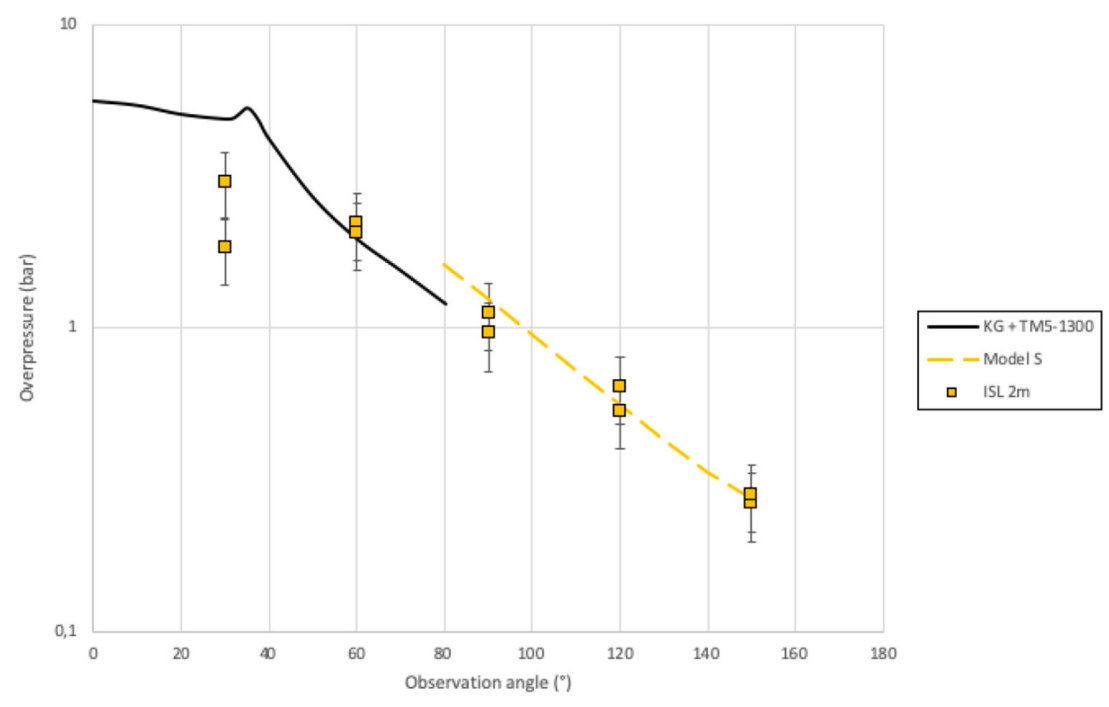

Figure 8: Overpressure evolution at $2 \mathrm{~m}$ in comparison with models [8-10, 18]. 


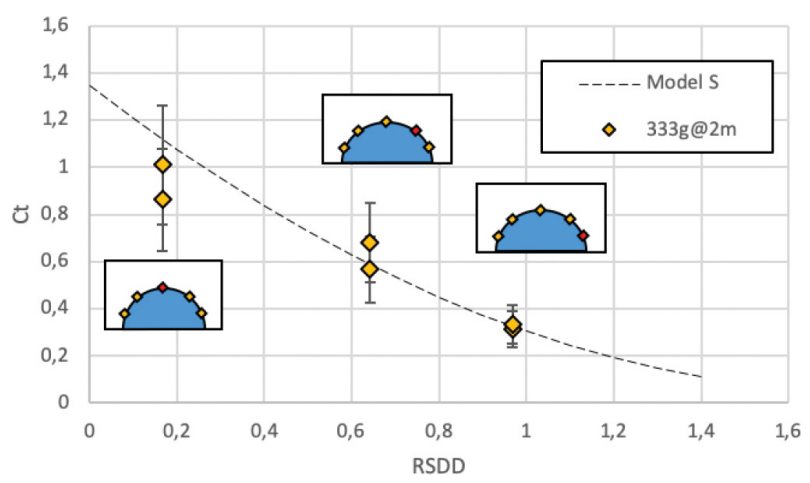

Figure 9: Transmission coefficient evolution with reduced shifted direct distance.

cally investigated using high-speed imaging of reflecting wave structure along its propagation around the obstacle. On all other angular positions, discrepancy never exceeds $23 \%$.

\subsection{Extension to other distances}

In order to validate Model S established using small-scale experimental results [18], we plotted all peak overpressure for larger scale results obtained at ISL (for $\mathrm{d}=0.8,1.2,2$ and $3.2 \mathrm{~m}$ ) versus observation angle on Fig. 10, as well as small-scale IRSN results performed by Trélat [18]. Model S complements the reflected face simplified model TM5-1300 + KG also represented to describe the centre line overpressure evolution, with a significant gap in between that remains to be addressed. In addition, we added colourful bars to materialize the regular reflection angular range before Mach reflection on the convex surface, experimentally determined at ISL using high-speed imaging. We note that these transition zones tend to appear later than the "knees" predicted by TM5-1300 + KG, valid for altitude explosions above

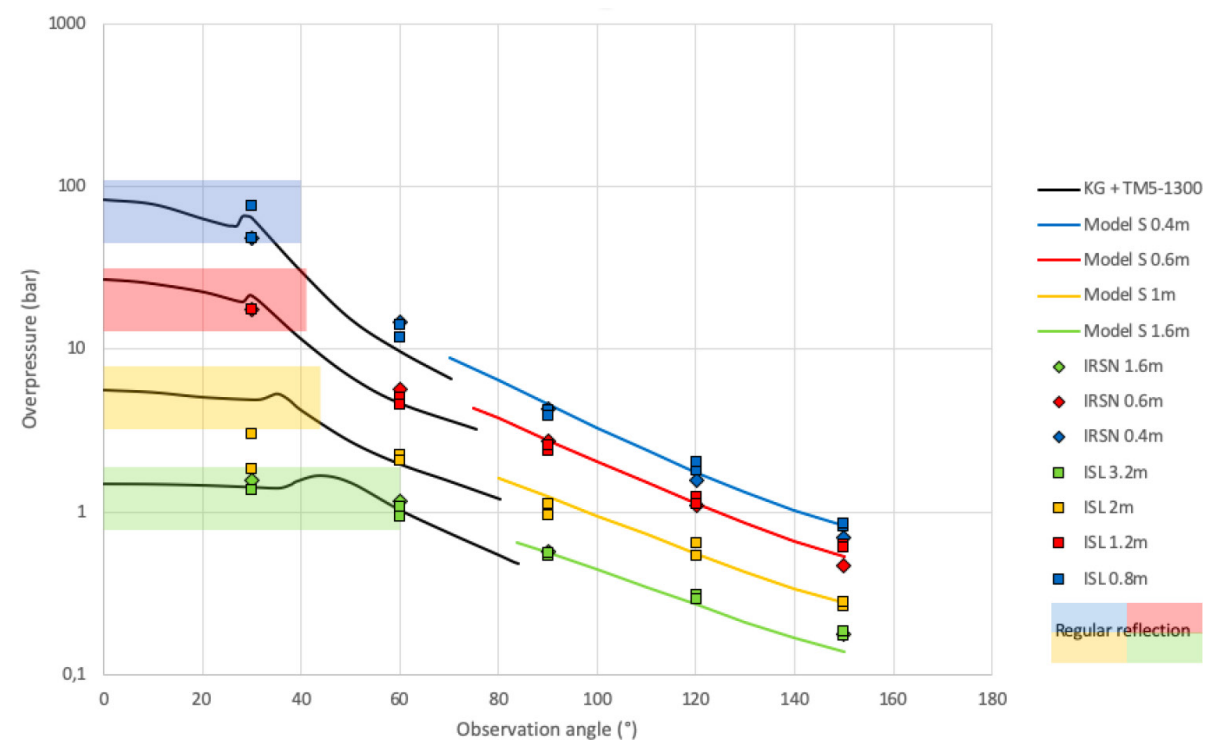

Figure 10: Overpressure evolution at $2 \mathrm{~m}$ in comparison with models [8-10, 18]. 
ground. Precise overpressure measurements on the hemicylinder surface would allow us to identify such pressure increase at transition, which is not always possible [21] because of the limited spatial and temporal resolutions linked to the sensors characteristics, as well as the difficulty to position the pressure sensors at the most relevant location. Relative deviations to models are illustrated on Fig. 11. We observe a quite good agreement below $30 \%$ in average between experiments and models except for the $2-\mathrm{m}$ distance at $30^{\circ}$ (corresponding to the two successive shocks described in 3.1). Model S tends to slightly overestimate peak overpressure at $90^{\circ}$ (10\% deviation in average) while underestimating at 120 and $150^{\circ}$ (respectively 8 and $12 \%$ deviation), which is visible on Fig. 12 representing evolution of transmission coefficient as a function of RSDD.

\subsection{Inter-scale comparison at $3.2 \mathrm{~m}$}

As the 2-m distance was not yet performed at IRSN, compared overpressure evolutions at both scales at $3.2 \mathrm{~m}$ (no data were acquired at $120^{\circ}$ at small scale and a thermal drift may have affected the $60^{\circ}$ sensor) are displayed on Fig. 13. IRSN time evolution was corrected by a factor 2 to take into account the scale difference. A good agreement in leading shock peak overpressure is observed despite a longer arrival time at ISL in comparison to IRSN values. These time discrepancies can be explained by a reactivity deficit of $12 \%$ in TNT equivalency of the largest charge and potentially attributed to ground nature, sensors, explosive charge average density, ignition and atmospheric conditions differences between both positions.

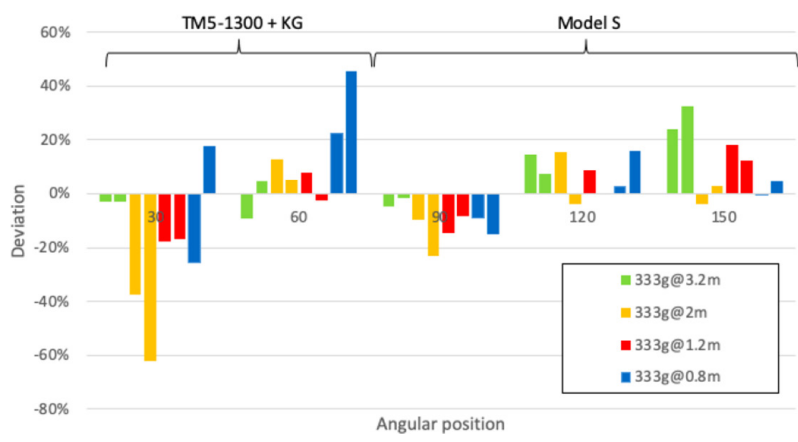

Figure 11: Deviation of measurement to models: KG + TM5-1300 at 30 and $60^{\circ}$, Model S at 90, 120 and $150^{\circ}$.

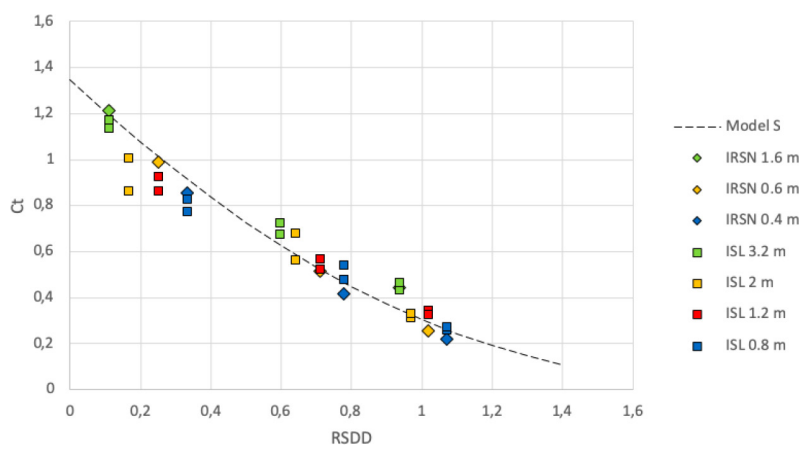

Figure 12: Evolution of transmission coefficient with reduced shifted direct distance. 

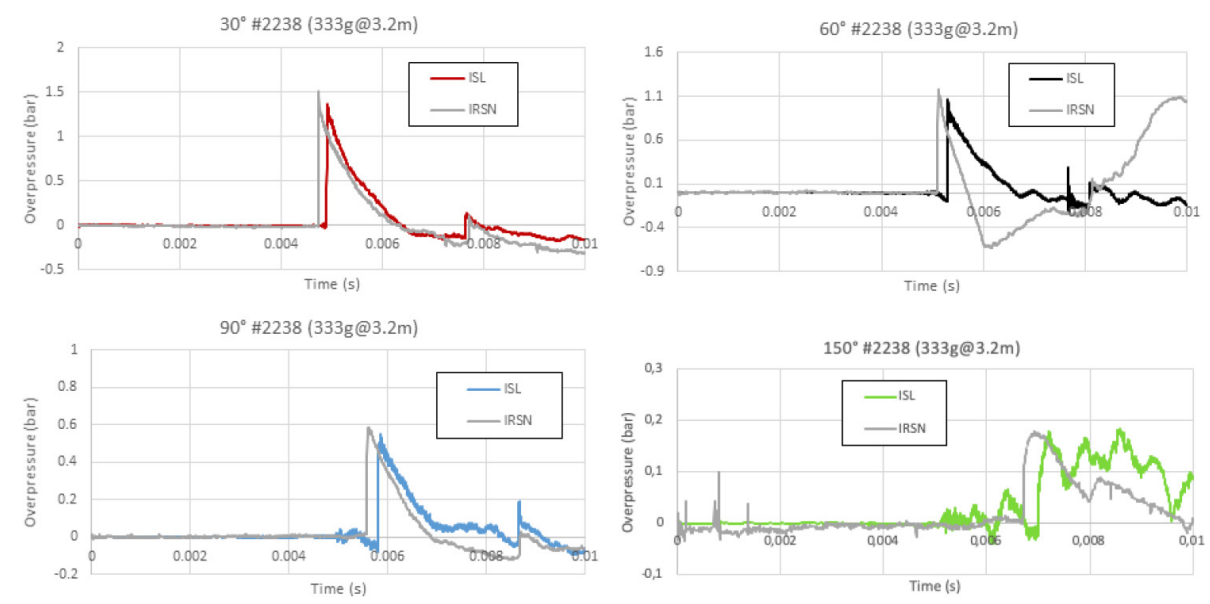

Figure 13: Overpressure evolutions at $3.2 \mathrm{~m}$ in comparison with scaled-up IRSN results.

Secondary shock arrival time is however similar for both configurations. At $150^{\circ}$, the composite wooden-based IRSN obstacle is significantly less affected by mechanical vibrations as the metallic ISL hemicylinder, leading to a more precise measurement of the successive peaks overpressures: an initial negative offset is clearly visible on the ISL evolution at the shock arrival time and the vibration amplitude appears to be in the same order of magnitude as the ground reflected and the secondary shocks. Finally, laterally by-passing shock waves may also affect the different shocks identification for the short ISL obstacle in comparison with the longer IRSN one.

\section{CONCLUSION AND PERSPECTIVES}

Blast wave interaction around a convex structure is presently being investigated at IRSN and ISL through two reduced scale studies conducted in parallel. A physical model predicting the overpressure evolution on the central line of the expansion side of a hemicylindrical obstacle was proposed in a previous document [18], on the basis of a small-scale experimental campaign conducted at IRSN. This Model S (overpressure evolution with the RSDD) complements the simplified procedure currently used to determine the peak reflected overpressures applied to the convex obstacle. This document presents the extension of the S-approach applicability domain to four distances between the charge and a shorter target at double scale. The adequation between experimental data and predictions confirms the model robustness. The discontinuity between the TM5-1300+KG and the Model S will however require to be bridged by refining the description of the reflected face using dedicated experiments. Full-cylinder-length ISL scale tests will need to be completed to further validate the Model S and determine the influence of the bypassing waves on the pressure load. Predictions will also need to be confronted to other obstacle diameter results to enhance the validity range of the model. Dedicated free-field pressure sensors should complement the hemicylinder instrumentation to confirm (or not) the observations made for the inter-scale analysis. Finally, the S-approach could also be extended to other obstacle shapes. This type of tool should contribute to perform structural finite element analysis or to improve the design of critical infrastructure by government agencies [5] in addition to other classic tools [17] able to predict average loading on blast-exposed surfaces. 


\section{REFERENCES}

[1] Cheval, K., Loiseau, O. \& Vala, V., Laboratory scale tests for the assessment of solid explosive blast effects. Part I: Free-field test campaign. Journal of Loss Prevention in the Process Industries, 23(5), pp. 613-621, 2010. https://doi.org/10.1016/j.jlp.2010.05.001

[2] Cheval, K., Loiseau, O. \& Vala, V., Laboratory scale tests for the assessment of solid explosive blast effects, Part II: Reflected blast series of tests. Journal of Loss Prevention in the Process Industries, 25(3), pp. 436-442, 2012. https://doi.org/10.1016/j. jlp.2011.11.008

[3] Trélat, S., Impact de fortes explosions sur les bâtiments représentatifs d'une installation industrielle, PhD Thesis, Université d'Orléans, France, 2006.

[4] Sochet, I., Blast Effects, Springer Verlag, 2018.

[5] Van Dorsselaer, N., Eveillard, S. \& Trélat, S., Experiments and simulations of explosives: shock wave propagation around a convex structure. Proceedings of the Fifteenth International LS-DYNA ${ }^{\circledR}$ Users Conference, 2018.

[6] Trélat, S., Sturtzer, M.-O., Eveillard, S., Eckenfels, D., Mory, J., Legendre, J.-F., Braina, F. \& Soubiès, B., Strong explosion near a convex structure: a multi-scale experimental study. Proceedings of the Twenty-fifth International Symposium on Military Aspects of Blast and Shock, 2018.

[7] Trélat, S. \& Sturtzer, M.-O., Predicting explosion and blast effects: a multi-scale experimental approach. International Journal of Safety and Security Engineering, 9(4). pp. 356-370, 2019. https://doi.org/10.2495/safe-v9-n4-356-370

[8] Kinney, G.F. \& Graham, K.J., Explosive shocks in air, Springer Verlag, 1985.

[9] TM5-1300, Technical Manual, Structures to Resist to the effects of Accidental Explosions, November, 1990.

[10] Duong, D.H., Hanus, J.L., Bouazaoui, L., Pennetier, O., Moriceau, J., Prod'homme, G. \& Reimeringer, M., Response of a tank under blast loading - part I: experimental characterization of blast loading arising from a gas explosion. European Journal of Environmental and Civil Engineering, 16(9), pp. 1023-1041, 2012. https://doi.org/10. 1080/19648189.2012.699741

[11] Glasstone, S \& Dolan, P.J., (3rd edition), The effects of nuclear weapons, Available from US Government Printing Office, 1962.

[12] Drikakis, D., Ofengeim, D., Timofeev, E. \& Voionovich, P., Computation of non-stationary shockwave/cylinder interaction using adaptive-grid methods. Journal of Fluids and Structures, 11(6), pp. 665-692, 1997. https://doi.org/10.1006/jfls.1997.0101

[13] Takayama, K. \& Kawauchi, T., The transition from regular to Mach reflection in truly non-stationary flows. Journal of Fluid Mechanics, 100, pp. 147-160, 1979. https://doi. org/10.1017/s002211208000105x

[14] Sturtzer, M.-O., Trélat, S. \& Sinninger, L., Investigation on the post-processing of blast loading characteristics along a convex structure, submitted to the Sixteenth International Conference on Structures under Shock and Impact, 22-24 June, Lisbon, Portugal, 2020.

[15] Grégoire, Y., Etude expérimentale et numérique de la dispersion explosive et de la combustion de particules métalliques, $\mathrm{PhD}$ Thesis, Ecole Nationale Supérieure de Mécanique et d'Aérotechnique, France, 2009.

[16] Trélat, S., Sturtzer, M.-O., Eckenfels, D., Mano C., Braina F. \& Legendre J.-F., High explosives blast propagation along a hemi-cylindrical obstacle: influence of pressure gauge technology on the overpressure characteristics, submitted to the Twenty-sixth 
International Symposium on Military Aspects of Blast and Shock, 15-20 November, Wollongong, Australia, 2020 (postponed).

[17] UFC 3-340-02, Structures to resist the effects of accidental explosions, Department of Defense USA, 2008.

[18] Trélat, S., Sturtzer, M.-O. \& Eckenfels, D., Multi-scale experimental study of blast propagation around a hemi-cylindrical barrier. WIT Transactions on the built environment, 198, pp. 53-64, 2020, ISSN: 1743-3509.

[19] https://www.pcbpiezotronics.fr/produit/capteur-de-pression/113b28/

[20] https://www.pcbpiezotronics.fr/produit/capteur-de-pression/m102a05/

[21] Dewey J.M., 53 Years of Blast Research - A Personal History, Proceedings of the Twenty-first International Symposium on Military Aspects of Blast and Shock, 2010.

[22] Genetier, M., Lefrançois, A., Suarez, J., Necysyn, N., Lavayssiere, M. \& Baudin, G., Secondary shock measurement comparison and validation to implement the post-combustion model, Proceedings of the Twenty-fifth International Symposium on Military Aspects of Blast and Shock, 2018.

[23] Gavart, R., Trélat, S., Sturtzer, M.-O. \& Eckenfels, D., Study of the propagation of blast waves generated by plastic explosives around hemicylindrical obstacles, ISL report R-04/16/03/000/0/00-00/RE-189/2020. 